\title{
A SIMPLE SINGLE-STEP IMMUNOIMMOBILISATION METHOD FOR THE DETECTION OF SALMONELLA IN THE PRESENCE OF LARGE NUMBERS OF OTHER BACTERIA
}

\author{
B. Mohit* $†$, R. Aly $\ddagger$ AND L. D. Bourgeois \\ $\dagger$ Department of Clinical Pathology, Clinical Center, National Institutes of Health, Bethesda, \\ Maryland; $\ddagger$ Department of Dermatology, University of California School of Medicine \\ San Francisco, California; and § Division of Allied Health Manpower, Bureau of Health \\ Professions Education and Manpower Training, Bethesda, Maryland, USA.
}

\section{Plate IX}

Numerous attempts have been made to simplify and improve the methods of detection of Salmonella (Rappaport, Konforti and Navon, 1956; Breed, Murray and Smith, 1957; Edwards and Ewing, 1962; Georgeala and Boothroyd, 1964; Haglund et al., 1964; Silliker, Diebel and Chiu, 1964; Silliker et al., 1965; Raj, 1966; Silliker, Schmall and Chiu, 1966; Insalata, Schulte and Berman, 1967; Abrahamsson, Patterson and Rueman, 1968). At present, however, most laboratories find it necessary to use the method recommended by Edwards and Ewing (1962).

Recently, a disk-immunoimmobilisation method for the typing of pure isolates of Salmonella was described (Mohit, 1968). We now report a similar procedure for the detection of Salmonella in human faeces. This method combines the use of the motility of these bacteria in soft agar, their selective growth in Salmonella-Shigella (S-S) medium and their immunoimmobilisation by polyvalent $\mathrm{H}$ antiserum in a single step.

\section{MATERIALS AND METHODS}

Preparation of media. S-S motility medium (SSM) was prepared by decreasing the agar content in the formula of S-S Medium (Difco, no. B74) to $3 \mathrm{~g}$ per 1 . The $p H$ of the medium was adjusted to 7.0 by addition of $\mathrm{NaOH}$. SSM $(15 \mathrm{ml})$ was poured into a sterile $10-\mathrm{cm}$ petri dish and cooled to room temperature. The lid of the petri dish was sealed on its plate by stopcock grease to prevent evaporation and hardening of agar during the incubation period. This precaution was found to be essential for the success of the technique.

Antiserum and preparation of disks. Salmonella polyvalent $\mathrm{H}$ antiserum was obtained from the National Communicable Disease Center, National Institutes of Health (NIH), Atlanta, Georgia, USA. Antiserum disks were prepared by impregnating absorbent paper disks (BBL no. 18-104v) with 1 drop of a 1 in 10 dilution of polyvalent $\mathrm{H}$ antiserum in Tris-albumin buffer (Mohit, 1968). In general, the disks were freshly prepared; however, they can be stored at $4^{\circ} \mathrm{C}$ for 10 days without losing activity.

Bacteria. Salmonella cultures were either isolated from NIH Clinical Center patients or referred to this laboratory from other hospitals.

Experimental procedure. The specimen $(0.02 \mathrm{ml})$ was inoculated on one side of an SSM plate and an antiserum disk was placed $7 \mathrm{~cm}$ from the site of the inoculum. The plate was left at room temperature $\left(24^{\circ} \mathrm{C}\right)$ and examined at 24 and $48 \mathrm{~h}$ for a semicircular line at the limit of opacity round the disk, caused by the growth and spreading of Salmonella and its immune immobilisation ("line of immobilisation": see figure).

The immunoimmobilisation method was compared with a standard method for detection of Salmonella in the following way. Fresh faeces $(5 \mathrm{~g})$ was suspended in $25 \mathrm{ml}$ of saline.

Received 13 July 1973; revised version accepted 15 June 1974.

* Present address: 1 Buckeye Way, Kentfield, Calif., USA. 
A pure broth culture of Salmonella was serially diluted with the faecal suspension. To a duplicate set of SSM plates and S-S agar plates, $0.02 \mathrm{ml}$ of each dilution of Salmonella in faeces was applied. The SSM plates were examined for the presence of lines of immobilisation. The S-S agar plates were used for the detection of Salmonella according to a standard method (Edwards and Ewing, 1962). The number of salmonellae detected by the two methods was determined by performing duplicate bacterial counts (agar pour-plate method) on the original Salmonella broth culture. In addition, stool specimens from 60 patients were screened by both methods.

\section{RESULTS}

Seven strains of Salmonella were tested in 12 experiments by the two methods; the table shows the sensitivity of each method for their detection. The immunoimmobilisation method was consistently more sensitive than the standard method. With the exception of $S$. typhimurium with the immunoimmobilisation method, wide variations in sensitivity were found with both methods when the same Salmonella was suspended in faeces from different persons. In the case of the 60 stool specimens screened by both methods, Salmonella was detected in two specimens by both. No false positives were noted.

Isolation of Salmonella detected by the immunoimmobilisation method was accomplished by removing a loopful of bacteria from the line of immobilisation and inoculating an S-S agar plate with it. The colonies grown on the latter were then tested by the standard method. All such colonies proved to be of Salmonella.

\section{Discussion}

The need for a simple, sensitive method for the detection of Salmonella is apparent from the large number of investigations devoted to devising such methods (Ino and Graber, 1955; Rappaport et al., 1956; Georgeala and Boothroyd, 1964; Haglund et al., 1964; Silliker et al., 1964; Raj, 1966; Insalata et al., 1967; Abrahamsson et al., 1968). An increase in the incidence of salmonellosis and of Salmonella contaminants in food and other materials has further accentuated this need (Insalata et al., 1967; Abrahamsson et al., 1968).

\section{TABLE}

Sensitivity of detection of Salmonella by immunoimmobilisation compared with that of a standard method

\begin{tabular}{c|l|rrr}
\hline $\begin{array}{c}\text { Experiment } \\
\text { number }\end{array}$ & $\begin{array}{c}\text { Salmonella } \\
\text { species }\end{array}$ & \multicolumn{2}{|c}{$\begin{array}{c}\text { Least number of Salmonella } \\
\text { detected by the }\end{array}$} & $\begin{array}{c}\text { Sensitivity } \\
\text { ratio* }\end{array}$ \\
& & $\begin{array}{c}\text { immunoimmobil- } \\
\text { isation method }\end{array}$ & $\begin{array}{c}\text { standard } \\
\text { method }\end{array}$ & \\
\hline 1 & & 1 & 10 & 10 \\
2 & S. typhimurium & 1 & 1000 & 1000 \\
3 & S. typhimurium & 1 & 10 & 10 \\
4 & S. typhimurium & 1 & 10,000 & 10,000 \\
5 & S. typhimurium & 1 & 10 & 10 \\
6 & S. chphimurium & 30 & 3000 & 100 \\
7 & S. paratyphi $B$ & 300 & 3000 & 10 \\
8 & S. montevideo & 3 & 300 & 100 \\
9 & S. enteritidis & 240 & 2400 & 10 \\
10 & S. blockley & 320 & 3200 & 10 \\
11 & S. typhimurium & 1 & 10 & 10 \\
12 & S. heidelberg & 2 & 200 & 100 \\
\hline
\end{tabular}

* Sensitivity ratio $=\frac{\text { least number of bacteria detected by standard method }}{\text { least number of bacteria detected by immunoimmobilisation }}$. 


\section{SALMONELLA IMMUNOIMMOBILISATION}

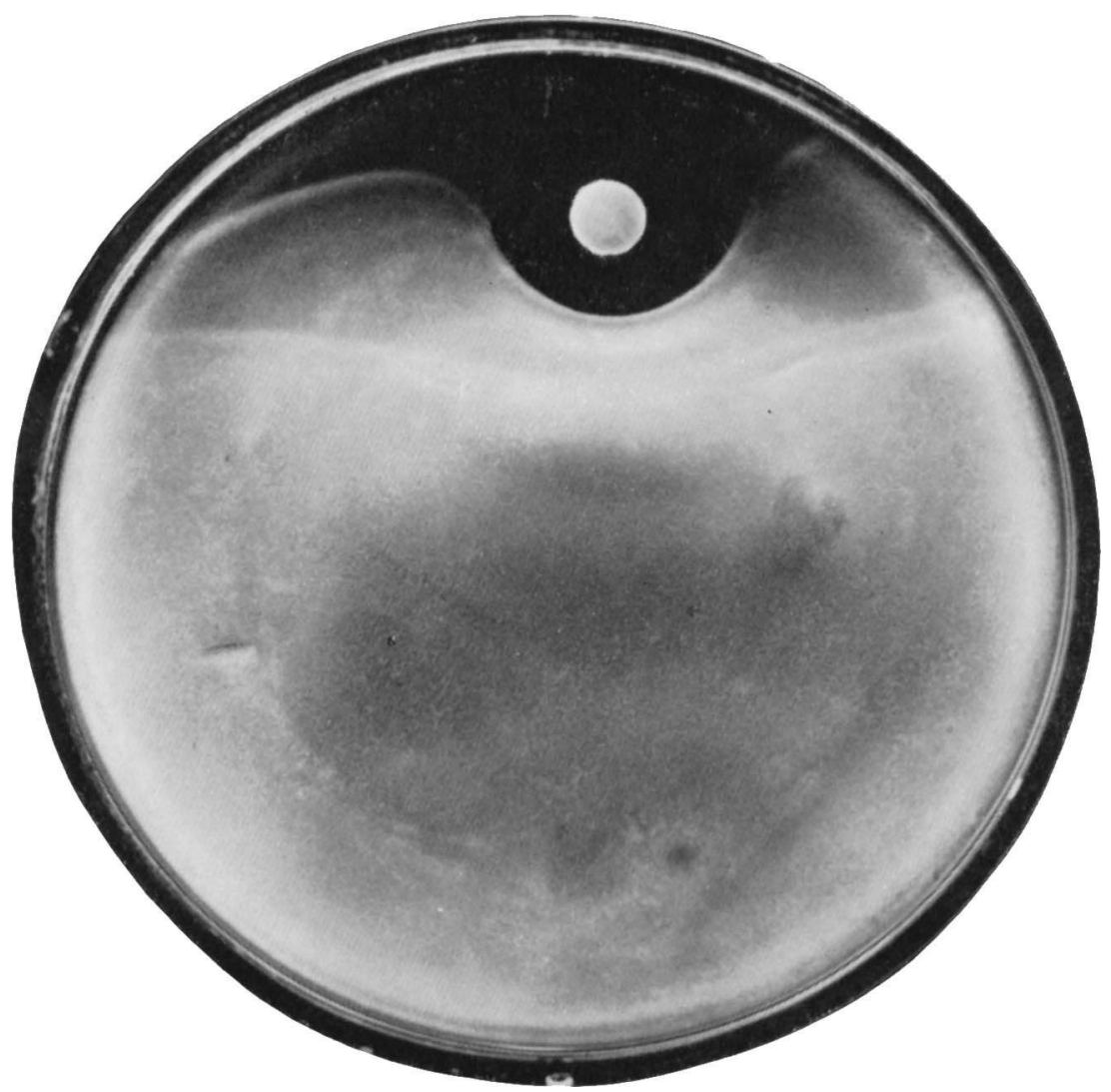

FIGURE-Demonstration of growth of Salmonella on S-S motility medium immobilised around a disk impregnated with polyvalent Salmonella $\mathrm{H}$ antiserum. 
The disk immunoimmobilisation method described in this report appears to be a simple and highly sensitive technique for detecting Salmonella in faecal samples. In most cases, as few as one Salmonella could be detected in the presence of a large number of bacteria in the stool. In this study, the volume of the specimen applied to each plate was $0.02 \mathrm{ml}$. This small inoculum was necessary for individual colony isolation required by the standard method. When low Salmonella concentrations are expected, as in stools of carrier individuals, the volume of inoculum in the immunoimmobilisation procedure may easily be increased 50 -fold and the probability of detection of Salmonella should be correspondingly increased.

No reason can be advanced for the variation in sensitivity of detection of a Salmonella according to the sample of faecal suspension with which it was diluted. Detailed bacteriological studies of different samples showed no apparent relationship between the nature of the bacterial flora they contained and the sensitivity of detection of the test organism.

No false positives were noted in this investigation. This is not surprising, because it has been demonstrated that $\mathrm{H}$ antisera are highly specific for the detection of Salmonella (Silliker et al., 1966).

It was further noted that when a salmonella was mixed with pure cultures of motile Proteus and Citrobacter in the ratio of 1 in 10,000 it was easily detected. No false positive results were obtained. Thus, although both Salmonella and certain other motile bacteria will grow on selective motility medium and spread toward the antiserum disk, the spreading of Salmonella alone is inhibited by the antiflagellar antibodies and its presence revealed by the formation of a line of immobilisation.

An inherent disadvantage of the technique is its inability to detect non-motile Salmonella. $S$. gallinarum and its variant, $S$. pullorum, are the only non-motile species of Salmonella; however, these are essentially fowl pathogens and are not significant in human salmonellosis (Breed et al., 1957). We do not propose that our method should be used as a substitute for other conventional methods. However, we do suggest that the technique devised in this study can shorten the time taken to detect salmonellae from faecal or other samples without loss of sensitivity, and that combining it with conventional methods provides a more efficient form of investigation.

\section{SUMMARY}

A single-step disk immunoimmobilistion method for the detection of motile salmonellae is described. It combines in a single step the use of the motility of these bacteria in soft agar, their selective growth on Salmonella-Shigella media, and their immobilisation by polyvalent $\mathrm{H}$ antiserum. The method is shown to be 10 to 10,000 times more sensitive than a standard method for detection of Salmonella under the experimental conditions used. The time required for detection is shortened to $24-48 \mathrm{~h}$.

\section{REFERENCES}

Abrahamsson, K., Patterson, G. and Riemann, H. 1968. Detection of Salmonella by a single culture technique. Appl. Microbiol., 16, 1695.

Breed, R. S., Murray, E. G. D. AND Smith, N. R. 1957. Bergey's manual of determinative bacteriology, 7 th ed,. Baltimore, p. 357.

EDWARDS, P. R. AND EWING, W. H. 1962. Identification of Enterobacteriaceae, Minneapolis, p. 92.

Georgeala, D. L. AND Boothroyd, M. 1964. A rapid immunofluorescence technique for detecting Salmonella in raw meat. J. Hyg., Camb., 62, 319.

Haglund, J. R., Ayres, J. C., Patow, A. M., Kraft, A. A. And Quinn, L. Y. 1964. Detection of Salmonella in egg and egg products with fluorescent antibody. Appl. Microbiol., 12, 447.

INo, J. AND GRABER, C. D. 1955 . Recovery of Salmonella from contaminated cultures. U.S. arm. Forces med. J., 6, 586.

Insalata, N. F., Schulte, S. J. AND Berman, J. H. 1967. Immunofluorescence technique for detection of Salmonella in various foods. Appl. Microbiol., 15, 1145.

J. MED. MICROBIOL.-VOL. 8 (1975) 
МонIт, B. 1968. Disc immuno-immobilization method for simultaneous typing and isolation of Salmonella flagellar phases. J. Bact., 96, 160.

RAJ, H. 1966. Enrichment medium for selection of Salmonella from fish homogenate. Appl. Microbiol., 14, 12.

Rappaport, F., Konforti, N. AND Navon, B. 1956. New enrichment medium for certain Salmonellae. J. clin. Path., 9, 261.

SILliker, J. H., DIEBEL, R. H. AND CHIU, J. Y. 1964. Occurrence of Gram positive organisms possessing characteristics similar to those of Salmonella and practical problem of rapid and definitive Salmonella identification. Appl. Microbiol., 12, 395.

Silliker, J. H., Fagan, P. T., ChiU, J. Y. AND Williams, A. 1965. Polyvalent H agglutination as rapid means of screening non-lactose-fermenting colonies for Salmonella organisms. Am. J. clin. Path., 43, 548.

Silliker, J. H., Schmall, A. AND ChiU, J. Y. 1966. The fluorescent antibody technique as a means of detecting Salmonella in foods. J. Fd Sci., 31, 240. 